\title{
(Im)Possibilidades da aplicação do Modelo de Excelência em Gestão Pública (MEGP)
}

\author{
Fernando Filardi \\ Grupo Educacional Ibmec / Programa de Mestrado em Administração \\ Rio de Janeiro / RJ - Brasil \\ Angilberto Sabino de Freitas \\ Universidade do Grande Rio (Unigranrio) / Doutorado em Administração \\ Rio de Janeiro / RJ - Brasil
}

\author{
Helio Arthur Irigaray \\ Fundação Getulio Vargas / Escola Brasileira de Administração Pública e de Empresas \\ Rio de Janeiro / RJ - Brasil
}

Ana Beatriz Ayres

Fundação Oswaldo Cruz (Fiocruz)

Rio de Janeiro / RJ - Brasil

\begin{abstract}
O presente artigo tem como objetivo identificar e analisar os resultados da aplicação do Modelo de Excelência na Gestão Pública (MEGP) na Fundação Oswaldo Cruz (Fiocruz) buscando avaliar os principais obstáculos culturais, burocráticos e políticos, no período de 2003 a 2011, conforme o Programa Nacional de Gestão Pública (Gespública). Trata-se de uma pesquisa exploratória e explicativa, na forma de um estudo de caso, com abordagem qualitativa, envolvendo a coleta de dados primários e secundários. Os resultados apontam para o cumprimento parcial dos objetivos do programa na instituição, pois se verificam melhorias decorrentes de sua implantação, porém barreiras culturais, burocráticas e de descontinuidade política precisam ser vencidas. Conclui-se que o modelo de excelência é um importante instrumento para as organizações públicas que desejem qualificar seus serviços, não sendo um pré-requisito o alinhamento total com o modelo.
\end{abstract}

Palavras-chave: Gespública; cultura; obstáculos.

(Im)Possibilidades de aplicación del Modelo de Excelencia en la Géstion Pública (MEGP)

Este artículo tiene como objetivo identificar y analizar los resultados de la aplicación del Modelo de Excelencia en la Gestión Pública (MEGP) en la Fundación Oswaldo Cruz (Fiocruz) en el período 2003-11,

DOI: http://dx.doi.org/10.1590/0034-7612142566

Artigo recebido em 6 nov. 2014 e aceito em 10 set. 2015. 
de acuerdo con el Programa Nacional para la Gestión Pública (Gespública). Se trata de una investigación descriptiva y explicativa en la forma de un estudio de caso con un enfoque cualitativo, que implica la recolección de datos primarios y secundarios. Los resultados de la encuesta apuntan al cumplimiento parcial de los objetivos del programa en la institución, como ocurre resultantes de su aplicación, sin embargo, las barreras culturales de discontinuidad, burocráticos y políticos tienen que ser superados.

Palabras clave: Gespública; cultura; barreras.

(Im)Possibilities for applying the Excellence in Public Management Model (MEGP)

This study aims at identifying and analyzing the results of the application of the Model of Excellence in Public Management (MEGP) in Oswaldo Cruz Foundation (Fiocruz), trying to evaluate the main cultural obstacles in the period from 2003 to 2011, according to the National Program of Public Management (GesPública). It is a descriptive and explanatory research, as a case study with a qualitative approach, involving the collection of primary and secondary data. The survey results point to the partial fulfillment of the goals of the program at the institution, as improvements occur arising from its implementation; however, cultural, bureaucratic and political discontinuity barriers need to be overcome. We conclude that the model of excellence is an important instrument for the public organization that want to qualify their services, not being a prerequisite the total alignment with the model.

Keywords: Gespública; culture; obstacles.

\section{Introdução}

As últimas duas décadas do século XX foram marcadas por mudanças significativas dos modelos de administração pública, os quais eram alvo de pesadas críticas por suas ineficiências e burocracias. As propostas de um novo modelo mais enxuto ficaram conhecidas como New Public Management (Nova Gestão Pública), em que se busca uma maior eficiência dos processos públicos (Goldfinch e Wallis, 2010), que foi implantado no Brasil, na gestão do presidente Fernando Henrique Cardoso, pelo Ministério de Administração e Reforma do Estado (Mare).

Nesse contexto, no âmbito do Programa Brasileiro de Qualidade e Produtividade (PBQP), foi criado em 1990 o Subprograma da Qualidade e Produtividade da Administração Pública, que passou a ter a finalidade de implantar programas de qualidade e produtividade nas entidades e instituições públicas, buscando torná-las mais eficientes na gestão dos recursos e no atendimento às demandas da sociedade (MPOG, 2009d:7).

Sano e Abrúcio (2008) afirmam que o modelo da Nova Gestão Pública (NGP) espalhou-se pelo mundo com a promessa de atacar dois males burocráticos: (i) o excesso de procedimentos e (ii) a baixa responsabilização dos burocratas em face do sistema político e da sociedade. Luedy, Mendes e Ribeiro-Junior (2012) complementam sustentando que essa nova fase aponta para um Estado mais regulador, em linha com o cenário do gerencialismo que

vem substituindo o Estado Intervencionista, em que as instituições vêm sendo submetidas a novas formas de controle e responsabilização. 
Assim, esse processo de mudança evoluiu na direção da gestão por resultados orientada ao cidadão, culminando em 2005 com o lançamento do Programa Nacional de Gestão Pública e Desburocratização (Gespública), cujo objetivo era simplificar os processos organizacionais das instituições públicas brasileiras, objetivando aumentar a competitividade desses órgãos (Ferreira, 2012).

Esse programa, apoiado em critérios de excelência, tem por objetivo promover o processo de autoavaliação, instrumentalizando uma gestão pública por resultados, alicerçada em um modelo de gestão pública singular que incorpora à dimensão técnica, própria da administração, a dimensão social, até então, restrita à dimensão política (Grin, 2013).

Diante dessas mudanças, argumenta-se: de que forma organizações com cultura forte, complexa e burocrática, como instituições voltadas para a saúde pública, são influenciadas pelas diretrizes sugeridas pela Gespública e como essas diretrizes se relacionam com suas diretrizes organizacionais? Para responder a essa questão de pesquisa conduzimos um estudo de caso na Fundação Oswaldo Cruz (Fiocruz), entre 2009 e 2012, em que foram realizadas entrevistas com servidores e consultados documentos oficiais públicos, submetidos posteriormente à análise de conteúdo, em que o objetivo foi avaliar o Gespública como sistema de gestão, analisando os resultados da sua implantação na Fiocruz, buscando avaliar os principais obstáculos culturais, burocráticos e políticos no período de 2003 a 2011 vis-à-vis as diretrizes organizacionais da instituição.

Por fim, apesar do crescente número de estudos que buscam investigar a Gespública (Akim e Mergulhão, 2015) este estudo se mostra relevante na medida em que preenche uma lacuna apontada por Resende-Júnior (2013) sobre a falta de pesquisas empíricas sobre o impacto das diretrizes sugeridas pelo Gespública, dentro do quarto focus (Souza e Araújo, 2003) da administração pública brasileira, a qual se ocupa da relação entre a economia e a administração pública, em que o governo necessita definir uma política de gestão que consiga articular desenvolvimento e crescimento econômico com democratização e transparência das ações estatais, com controle social sobre a administração pública. Ademais, no nosso movimento de saída do campo, entregamos resultados desta pesquisa aos gestores da Fiocruz, os quais os consideraram fundamentais para que fosse conduzido o projeto de (re)alinhamento dos processos da instituição com suas diretrizes organizacionais.

\section{Marco teórico}

\subsection{Progressão da administração pública no Brasil}

A produção científica contemporânea na administração pública brasileira possui alguns trabalhos considerados clássicos e que têm auxiliado na consecução da trajetória dos estudos e pesquisas que visam ampliar e aprimorar o campo da administração pública brasileira (Machado-da-Silva, Amboni e Cunha, 1989; Fischer, 1984, 1993). 
Com o intuito de mapear autores, buscando vincular as suas temáticas pesquisadas, sistematizando um balanço da literatura do campo da gestão pública, Souza e Araújo (2003), com base em Keinert (2000), agrupam os estudos em cinco focus:

(i) o primeiro focus pós-burocrático busca detalhar os principais aspectos das inovações e das novas práticas de gestão, juntamente com o movimento gerencialista, entendido como uma vertente pós-burocrática. Enfatiza-se que, em parte, essa vertente pós-burocrática assume alguns pressupostos e focus da ciência política, que vem sendo, destacadamente, preconizado por autores como Barzelay (1994), Abrúcio (1997), Bresser-Pereira (2008, 2009), Bresser-Pereira e Spink (1996, 2001), entre outros.

(ii) o segundo focus aborda os impactos da globalização no aparelho do estado brasileiro e em alguns países, identificando aqueles que fizeram as chamadas reformas estruturais do Estado e da administração pública. Analisa e avalia os principais impactos da globalização econômica na capacidade gerencial dos governos, preconizando a ampliação da governança e das capacidades institucionais, sugerindo e propondo políticas e programas de desregulamentação, privatização de instituições e empresas do Estado e flexibilização das organizações públicas (Kouzmin, 1998; Farmer, 1998; Haque, 1998).

(iii) o terceiro focus aborda os condicionantes da ordem política, econômica e social, em que se faz uma crítica ao tipo de inserção do Brasil na economia mundial globalizada, sem considerar aspectos regionais e locais, somando-se à importação de modelos econômicos e práticas de gestão privadas, desconectados da realidade social brasileira.

(iv) o quarto focus se refere às novas tendências no ciclo de políticas públicas. Uma vez que, cada vez mais, se enfatiza a questão das políticas públicas como importante instrumento para distribuição de rendas e de reinserção social para os segmentos mais pobres, tem-se observado nesse focus uma relevância de estudos mais neoinstitucionalistas, explorando o papel, a natureza e a importância das instituições e das relações Estado-sociedade, políticos e burocratas, cidadãos e governo e Estado-administração pública. O mais importante eixo desse focus é a questão da relação entre a economia e a administração pública, em que o governo necessita, urgentemente, definir uma política de gestão que, para além das questões econômicas, consiga articular desenvolvimento e crescimento econômico com democratização e transparência das ações estatais, com controle social sobre a administração pública. Mello (2002) é um autor importante nesse campo.

(v) o quinto e último focus tem uma preocupação com a gestão das políticas sociais no Brasil e no continente latino-americano. Com o aumento da pobreza em nosso continente e, em particular, no Brasil, com relações trabalhistas precárias e falta de qualificação profissional dos trabalhadores, os governos se veem obrigados a priorizar a formulação e implementação de políticas sociais mais emancipatórias e redistributivas de renda. Autores como Dowbor (1998) e Fleury (2003), entre outros, são destacadamente alguns dos pesquisadores mais importantes na gestão das políticas sociais no Brasil. 


\subsection{Gespública}

Não se pode falar de Gespública sem antes compreender o que é qualidade e apontar os principais eventos que buscam premiar organizações e empresas que primam pela excelência de seus processos e serviços.

A definição de qualidade é um exercício desafiador. É mais fácil perceber a qualidade do que propriamente definir o que é qualidade. Reeves e Bednar (1994) argumentam que não existe uma definição global e que diferentes definições de qualidade podem surgir de acordo com diferentes contextos e circunstâncias, tornando-o um fenômeno complexo. Por exemplo, a qualidade está associada ao valor percebido pelo indivíduo (Weinberg, 1991), ou cidadão, no caso do serviço público (Carr e Littman, 1992), à melhoria de processos (Deming, 1990), à ausência de defeitos (Juran, 2004), ou, ainda, conformação às especificações (Crosby, 1979).

Dada a importância que a busca pela qualidade passou a ter para que empresas e organizações possam se manter competitivas, diversos organismos buscam premiar aquelas organizações que conseguem atingir a excelência em termos da qualidade alcançada. Dois prêmios se destacam como os mais importantes: (1) o prêmio Deming (Evans e Lindsay, 1993) e (2) o Malcolm Baldrige National Quality Award (Baldrige, 2014).

O Prêmio Deming é um prêmio de qualidade global que reconhece os indivíduos por suas contribuições para o campo da Gestão da Qualidade Total (GQT) e as empresas que implementaram com sucesso esse programa. É o prêmio mais antigo e mais amplamente reconhecido sobre qualidade no mundo (Evans e Lindsay, 1993).

O Prêmio Malcolm Baldrige premia a excelência do desempenho de organizações norte-americanas de negócio, saúde, educação e setores sem fins lucrativos. O Prêmio Malcolm Baldrige é o único reconhecimento formal de excelência tanto de organizações públicas quanto privadas. É administrado pelo Programa de Excelência de Desempenho Baldrige e gerido pelo Instituto Nacional de Padrões e Tecnologia, uma agência do Departamento de Comércio dos EUA.

Para avaliar as organizações, o prêmio Malcolm Baldrige usa três critérios: (1) os critérios de excelência de desempenho, (2) valores e conceitos básicos e (3) diretrizes de pontuação. A estrutura tem duas finalidades principais: (1) ajudar as organizações a avaliar seus esforços de melhoria, diagnosticar seu sistema global de gestão de desempenho, e identificar seus pontos fortes e oportunidades de melhoria e (2) identificar os destinatários que servirão como modelos para as organizações.

No âmbito do Brasil, foi instituído em 1992 o Prêmio Nacional da Qualidade (PNQ) seguindo os critérios do Prêmio Malcolm Baldrige. O PNQ está a cargo da Fundação para o Prêmio Nacional da Qualidade (Rossi e Slongo, 1998).

No que diz respeito à administração pública brasileira, esses prêmios inspiraram o desenvolvimento de programas que estimulassem a busca pela excelência em termos de qualidade e produtividade (Ferreira, 2003). De 1990 a 2005, quatro marcos caracterizaram a evolução dos programas de qualidade e produtividade da administração pública brasileira (quadro 1). De acordo com Ferreira (2012), a abertura econômica iniciada no início dos anos 1990 
estimulou o Estado a implantar modelos de gestão que preparassem as instituições públicas para as novas demandas de uma sociedade em vias de globalização.

Quadro 1

Retrospectiva do Programa Nacional de Gestão Pública e Desburocratização

\begin{tabular}{|ccccc|}
\hline Ano & 1990... & 1996... & 2000... & 2005 \\
\hline Programa & $\begin{array}{c}\text { Pubprograma da } \\
\text { Qualidade e Produtividade } \\
\text { na Administração Pública }\end{array}$ & $\begin{array}{c}\text { Programa da Qualidade } \\
\text { e Participação na } \\
\text { Administração Pública }\end{array}$ & $\begin{array}{c}\text { PQSP } \\
\text { Programa da }\end{array}$ & $\begin{array}{c}\text { GESPÚBLICA } \\
\text { Programa Nacional } \\
\text { de Gestão Pública e } \\
\text { Objetivos do } \\
\text { Programa }\end{array}$ \\
\hline
\end{tabular}

Fonte: MPOG (2009d).

O primeiro grande marco foi a criação em 1990 do Programa Brasileiro da Qualidade e Produtividade (PBQP), que gerou o Subcomitê da Administração Pública, iniciando a era dos Programas de Qualidade no Serviço Público. Na sequência, em 1996, foi lançado o Programa da Qualidade e Participação na Administração Pública (QPAP), aproveitando a nascente Reforma do Estado, mas ainda com foco nos mecanismos voltados para a qualidade como instrumento de modernização do Estado.

No início do novo milênio, em 2000, foi criado o Programa da Qualidade no Serviço Público (PQSP), no âmbito do Ministério do Planejamento, Orçamento e Gestão (MPOG), somando todo o aprendizado das experiências anteriores, porém agora com foco na qualidade do atendimento ao cidadão. Finalmente, em 2005, o governo federal institui, por meio do Decreto no 5.378, de 23 de fevereiro de 2005, o Programa Nacional de Gestão Pública e Desburocratização (Gespública), agregando o Programa da Qualidade ao Programa Nacional de Desburocratização, e focando essencialmente em contribuir para a melhoria da qualidade dos serviços públicos prestados aos cidadãos e para o aumento da competitividade do país mediante melhoria contínua da gestão pública.

As premissas centrais do Gespública descritas no Documento de Referência (MPOG, 2009d) são:

I. ser de natureza pública, considerando que a gestão pública pode e deve ser

II. excelente, mas não pode nem deve deixar de ser pública na sua configuração;

III. ser focada em resultados e demandas da sociedade ao se afastar da lógica de um

IV. serviço público apegado às normas da burocracia, de modo que a eficiência e a eficácia sejam avaliadas pela capacidade da gestão pública em melhorar a qualidade de vida dos cidadãos; 
V. ter um caráter federativo e republicano, pois sua base conceitual e seus instrumentos VI. são aplicáveis a toda administração pública, seus poderes e outras esferas de governo.

A rigor, a gestão por resultados tem o propósito de estimular a avaliação de desempenho, vinculados à remuneração ou à progressão de carreira, atrelada a resultados individuais ou organizacionais (Favero, 2010). O processo de modernização da gestão pública com preocupação nos resultados instaurou uma nova dinâmica no setor público, com a aplicação de sistemas de indicadores que facilitam a identificação e atingimento dos objetivos e metas a serem perseguidos (Bresser-Pereira e Spink, 2006). Assim, a avaliação de desempenho é uma ferramenta de legitimação e racionalização da gestão de modo a se ter um instrumento de acompanhamento para avaliação pela sociedade (Teixeira e Santana, 1995).

Num sistema ideal de avaliação de desempenho, a complexidade das informações dos dados como recursos e materiais até os resultados e impactos - seria utilizada pelos gestores públicos dentro de uma lógica na qual a vinculação entre o monitoramento do desempenho (de processos, eficiência e produção) e a avaliação do desempenho (dos resultados e impactos) seria utilizada para orientar o planejamento estratégico de um programa, bem como para aprimorar seu desempenho no futuro (Favero, 2010).

Apesar do intuito do governo em buscar promover uma maior eficiência de seus processos e serviços, ao instituir programas de qualidade inspirados em modelos estrangeiros de sucesso, pode-se identificar deficiências, como as apontadas por Ferreira (2003): (i) os fundamentos que sustentam o modelo de excelência precisam ser testados e confirmados para potencializar a aplicação da avaliação da gestão a fim de torná-la cada vez mais consistente; (ii) o pouco uso das informações produzidas pelo Plano de Qualidade do Governo Federal (PQGF) evidencia a baixa prioridade da gestão por políticos e altos dirigentes da máquina pública. Além do mais, limitações de recursos humanos e materiais podem frear os avanços necessários para se atingir os objetivos propostos. O que se viu foi que, ao longo dos cinco primeiros anos do PQGF, ele se estruturou com ênfase no processo de avaliação, mas falhou em desenvolver mecanismos de comunicação e marketing adequados para o seu universo de clientes potenciais (Ferreira, 2003:80).

O que se percebe é que, para a mensuração do desempenho organizacional na administração pública gerencial, o enfoque tem sido deslocado dos processos para os resultados, o que leva à necessidade de uma mudança na cultura do setor público para uma missão voltada mais para a sociedade, em que se busca criar uma estrutura flexível e de liberdade para que os objetivos sejam alcançados. O resultado são produtos e serviços de qualidade.

Particularmente, no que tange à administração pública, o gerenciamento da qualidade busca, por meio da mudança da cultura organizacional, "modificar as relações institucionais, transformando chefes e subordinados em parceiros que busquem atingir as metas da organização" (Gomes, 1997:51).

A cultura organizacional, por sua vez, deve ser analisada em três níveis: dos artefatos, em que os rituais, os símbolos, as estruturas e os processos organizacionais visíveis represen- 
tam os fatores mais importantes de serem observados; dos valores compartilhados, no qual as estratégias, metas e filosofias ganham destaque; e, finalmente, no das suposições básicas subjacentes, em que as crenças, as percepções e os sentimentos inconscientes e enraizados representariam os dados a serem analisados (Schein, 1985).

Na prática, a adoção da gestão da qualidade por uma instituição se baseia no alinhamento das estruturas hierárquicas a partir do nível decisório até as chefias setorizadas, modificando a estrutura administrativa, tornando-a mais ágil e flexível, o que reduz o retrabalho e, consequentemente, os custos operacionais (Malik e Schiesari, 2002). No limite, busca-se mudar o comportamento dos servidores, os quais passariam a encarar suas tarefas com perspectivas mais globalizadas e a ver o contribuinte como um "cliente", cujas necessidades precisam ser satisfeitas. Para que isso aconteça, cabe aos gerentes agir em regime de parceria com seus subordinados, em vez de obstruir o sistema de informações na busca de legitimidade e poder (Paladini, 2009).

Assim, princípios de modelo de gestão pública da qualidade, preconizados no Gespública, são: (i) o servidor público é a mola propulsora para geração da qualidade; (ii) a motivação deve ser o elemento básico para o envolvimento e comprometimento do funcionário; (iii) a propriedade que caracteriza a qualidade no serviço público é a transitividade, isto é, o funcionário repassa para a sociedade os benefícios de sua satisfação com o trabalho e com base em suas relações com o empregador, nesse caso, o Estado; e, (iv) o programa deve envolver objetivos de curto, médio e longo prazos.

Todavia, esse modelo de gestão da qualidade é norte-americano e, para ser aplicado, devemos levar em consideração as especificidades da cultura brasileira (Prestes Motta e Caldas, 1997). Por exemplo, o modelo de gestão pública se caracteriza pela cultura da estabilidade do servidor público, o monopólio da prestação da quase totalidade de serviços em áreas específicas, os baixos salários, a falta de qualificação de pessoal e cultura tradicional de descaso à coisa pública como pontos a serem tratados para se obter uma gestão eficiente (Paladini, 2009).

Outras barreiras foram apontadas por Fowler, Mello e Costa Neto (2011) no que diz respeito ao papel gerencial para garantir a motivação dos envolvidos no processo de implementação desse tipo de programa de gestão de qualidade. Alguns desses agravantes são: (i) apego à burocracia; (ii) recursos considerados insuficientes; (iii) falta de comprometimento; (iv) quadro reduzido de servidores; (v) pressão das partes interessadas e, por fim; (vi) inexperiência institucional com programas da qualidade. Tais entraves funcionam como impeditivos para que uma mudança gerencial para a qualidade possa ser implantada. Fowler, Mello e Costa Neto apontam que cabe ao gestor ter coragem e energia para romper com essas barreiras e avançar rumo à excelência.

Em uma ampla revisão da literatura, Karyotakis e Moustakis (2014) apontam os principais aspectos que dificultam a implementação de programas de qualidade na administração pública: (i) excesso de burocracia; (ii) dificuldade em tratar o cidadão como cliente; (iii) corrupção; (iv) arbitrariedade do governo; e (v) atrasos nos procedimentos governamentais. Entretanto, concluem que para uma efetiva implantação desses programas é necessário enfatizar que a melhoria da qualidade somente é conseguida por meio de um esforço mútuo por parte 
de todos os trabalhadores. Portanto, é fundamental cultivar uma mentalidade de qualidade (cultura da qualidade) em toda a organização para que os trabalhadores desenvolvam uma maturidade para aceitar o modelo de gestão da mudança. Essa cultura deve vir acompanhada de um eficiente processo de comunicação, respeito e apreço entre os colegas, bem como entre colegas e cidadãos. A adoção da cultura de qualidade requer um compromisso contínuo da gerência sênior para com a qualidade.

Hoje, a avaliação da administração pública brasileira se encontra institucionalizada (Akim e Mergulhão, 2015) basicamente na função do controle, com ênfase no cumprimento dos requisitos legais, principalmente, os ligados aos recursos financeiros, que são limitados, já que transitam no curto caminho entre o previsto e o realizado. Entretanto, não considera resultados em longo prazo, caminho que deveria percorrer, e, conforme atesta Camilo (2003), há uma prática de avaliação ainda rara na administração pública brasileira: a avaliação do sistema de gestão.

Para o Gespública, avaliar é comparar o sistema de gestão de um órgão ou entidade pública com o Modelo de Excelência em gestão pública (Lima, 2007), verificando a aderência das práticas gerenciais a esse modelo. Essas práticas são as unidades celulares da avaliação e têm o objetivo de condução das funções de uma organização. A função da avaliação não é transformar nem produzir qualidade, mas, sim, em caso de comparação, sinalizar para a melhoria da gestão. Melhorar um sistema de gestão é continuamente aprimorar um conjunto de práticas de forma a produzir aprendizado e mudança de hábito. É um processo complexo, lento e não se limita a recursos burocráticos relativos às normas e, sim, a recursos mais simples de métodos e ferramentas, mudança de organograma, entre outros. A avaliação também implica refletir sobre como as práticas são realizadas.

Infere Lima (2007) que o diferencial de qualidade da avaliação está no tipo de mudança que ela promove. No processo de avaliação, a organização deve se autoavaliar. A autoavaliação é um evento interno da organização, sistematizada e compartilhada com todos os servidores, e compreende a avaliação das práticas de gestão e resultados da organização. É uma reflexão da organização sobre si mesma.

Para se obter um equilíbrio da qualidade com as práticas de gestão, seis critérios de avaliação devem ser levados em consideração: (i) Liderança; (ii) Estratégias e Planos; (iii) Cidadão e Sociedade; (iv) Informação e Comunicação; (v) Pessoas; e (vi) Processos. Assim, pressupõe-se como sinal de qualidade do sistema de gestão a evidência (ou não) de os resultados serem consequência direta destas práticas (MPOG, 2009b).

Nesse sentido, o Gespública possui um sistema de pontuação com o objetivo de determinar o grau de maturidade da gestão da organização nas dimensões de processos gerenciais e resultados. O instrumento para avaliação está estruturado em oito critérios, 25 itens e 111 alíneas. Cada item é composto de alíneas que representam os requisitos do item e a avaliação da gestão da organização é feita com base em duas dimensões: (i) processos gerenciais e (ii) itens de resultados.

O Gespública foi concebido, desenhado e implementado por funcionários do topo e deveria ser executado pelos atores dos médio e baixo escalões. Mas delegar a alguém atribui- 
ções é sempre arriscado porque, embora a designação seja feita a papéis, "de fato a delegação necessariamente envolve indivíduos concretos que têm interesses e objetivos que nem sempre coincidem com os do sistema formal" (Selznick, 1948:27). De fato, os envolvidos podem apresentar resistências às diretrizes que acompanham a delegação e, valendo-se do seu poder de agência, podem se desviar das normas e dos procedimentos formais no cotidiano; ou seja, violando a lógica prescrita dentro da burocracia weberiana (Brelaz e Alves, 2013).

A rigor, a relação hierárquica entre o topo e a base da pirâmide organizacional pode induzir ao entendimento de que os que se situam embaixo deveriam executar sine ira et studio as ordens emanadas de cima (Grin, 2014); isto é, o tipo-ideal weberiano se desvia consideravelmente das burocracias do nível da rua (Lipsky, 1980), porque seus operadores desfrutam de ampla autonomia na decisão sobre as práticas e operações propriamente ditas (Oliveira, 2012). Ademais, os funcionários não necessitam, necessariamente, violar as regras para não cumprir as ordens oriundas de cima (Downs, 1967). Ao contrário, eles podem usá-las para justificar sua resistência. Ou seja, se a norma obriga, por outro lado, ela protege também o agente na ponta do sistema. Como as condições reais de trabalho estão geralmente aquém não só das ideais como das necessárias, legitimamente os atores podem se recusar a trabalhar sob as condições existentes na agência ou, outro recurso à disposição, podem realizar as tarefas de acordo com a letra da lei (Mechanic, 1962).

\section{Percurso metodológico}

Tendo em vista a pergunta investigativa que instigou esta pesquisa, conduzimos um estudo de caso na Fiocruz de cunho qualitativo, baseado em pesquisa participante, dado que é o local de trabalho de um dos autores, que participou do processo de implementação da Gespública.

A coleta de dados para este estudo foi por meio de documentos oficiais da instituição (atas, relatórios, leis, regulamentações, portarias, normas do Ministério do Planejamento, Orçamento e Gestão e do próprio governo), observações (confraternizações, conversas informais com os servidores e funcionários). Além do mais, dado nosso interesse em apreender o significado das percepções, sensações e sentimentos vivenciados pela experiência humana (Merrian, 1998), nesse caso em particular pelos gestores da Fiocruz em relação ao processo de implantação do Gespública, foram realizadas entrevistas entre os meses de janeiro e julho de 2012 com todos os membros do comitê responsável pela implantação do programa: os dois dirigentes do comitê subsetorial do Gespública na organização, a coordenadora do comitê gestor para a qualidade e os sete membros do comitê gestor para a qualidade, com cargos de gerência em diferentes setores estratégicos da organização, totalizando 10 entrevistas. As observações foram catalogadas em notas de campo, nas quais foram anotadas nossas impressões, vivências como servidor, bem como conversas e comentários informais.

A seleção para a realização das entrevistas obedeceu ao critério de representatividade e acessibilidade, já que foram selecionados os profissionais que compõem o Grupo Executivo 
Gespública, por estarem à frente de atividades ligadas às questões relacionadas com esta pesquisa e também por terem tido participação ativa no processo.

As entrevistas foram conduzidas com base num roteiro aberto que se dividiu em três etapas: a primeira, na qual focamos os dados categóricos (formação acadêmica do respondente, cargo, função, tempo de casa); a segunda, que tratou da trajetória profissional do respondente dentro da empresa, e a terceira, e última, que aprofundou as percepções sobre as mudanças no ambiente, estrutura, estratégia, processos e práticas organizacionais em função da implantação do Gespública. Os principais pontos de interesse das entrevistas foram norteados pelos princípios e fundamentos do Modelo de Excelência na Gestão Pública (MEGP) e embasados pelos dados teóricos.

As entrevistas foram gravadas e transcritas e, assim como os relatórios, foram submetidas à análise de conteúdo (Bardin, 1977), e nos valemos, prioritariamente, da lexicometria. A repetição constante de termos indicou também a saturação do campo.

Por seu caráter qualitativo, a noção de confiabilidade, isto é, em que medida os mesmos resultados de uma pesquisa são obtidos em tentativas repetidas, não é uma medida relevante nesse tipo de metodologia. Todavia, foi buscado garantir a acurácia e a validade desta pesquisa.

A acurácia, por sua vez, reflete em que medida o procedimento metodológico é unbiased (Potter e Levine-Donnerstein, 1999), ou seja, não tendencioso. Nesse sentido, buscamos a imparcialidade por meio do consenso da categorização entre os quatro pesquisadores.

Já a validade espelha se as categorias utilizadas representam o objeto de estudo (Bechtel, 1993). Dado o caráter qualitativo da metodologia aqui utilizada, não se pode aferir a chamada validade externa (grau de generalização), mas apenas a validade interna, a qual reflete o alinhamento entre as definições conceituais e a operacionalização per se (Gottschalk, 1995), por meio da validade de face (Neuendorf, 2012), isto é, a repetição da categorização diversas vezes, no sentido de verificar se os mesmos resultados se repetem; ou seja, nesse caso especificamente, validamos nossos dados por meio da triangulação com os documentos obtidos, nomeadamente, os relatórios de autoavaliação de gestão dos períodos de 2003, 2008-09 e 2010-11 que foram disponibilizados. Na pesquisa aqui apresentada, tomando como base fragmentos de discursos e seleções lexicais dos textos analisados, foram identificadas, por meio da taxonomia do constructo (Stiles, 1993), quatro categorias abertas de análise: a axial: implantação e adequação ao Programa; as Resistências, barreiras e dificuldades na implantação do programa; os impactos; e o comprometimento com a gestão pública por resultados.

\section{Resultados da pesquisa}

A análise dos resultados foi desenvolvida seguindo a mesma lógica utilizada no roteiro e, portanto, a apresentação foi organizada em quatro blocos. O primeiro corresponde ao contexto da implantação e adequação da Fiocruz ao Gespública e buscou explorar como os participantes veem as ações e aprimoramentos que devem ser realizados. O segundo bloco corresponde às resistências, barreiras e dificuldades na implantação do programa, ou seja, as primeiras 
percepções e impressões sobre a intervenção e os desafios da sua implantação. O terceiro item é destinado à análise dos impactos relacionados às ações diretas realizadas para a busca da excelência. E, por fim, o quarto bloco busca compreender como o comprometimento da alta direção para o desenvolvimento das atividades contribui para o alcance dos resultados esperados na implantação do Gespública.

\subsection{Implantação e adequação ao Gespública}

Na Fiocruz, a adoção dos critérios de excelência da gestão pública foi formalizada pela Portaria n⿳⺈ 313/2007, de 13 de julho de 2007, que criou o Comitê Subsetorial Gespública Fiocruz, com representação de todas as unidades da Fiocruz e coordenação da Diretoria de Planejamento. Sua adoção visa direcionar a Fiocruz em sua transformação gerencial e, ao mesmo tempo, permitir avaliações comparativas de desempenho com organizações públicas brasileiras e estrangeiras. A sua importância está no processo de melhoria contínua da gestão na Fiocruz, com impacto na qualidade de seus produtos (Fiocruz, 2009).

A categoria axial, que se refere à implantação e adequação ao Gespública em seus critérios de excelência, foi diagnosticada em dois diferentes momentos. O primeiro por comentários, documentos e reuniões que entendiam que o aprimoramento do projeto de excelência da gestão pública (Gespública) da Fiocruz deveria ser encaminhado por meio de iniciativas corporativas e/ou individualizadas (via candidatura ao Ministério do Planejamento, Orçamento e Gestão/MPOG por unidade).

Para os servidores, esse processo de aprimoramento compreende a modelagem de processos estratégicos, a gestão da rede de atores, a ferramenta gerencial conhecida como benchmarking, a instituição de modelo gerencial de aprendizagem, bem como a elaboração do plano de risco organizacional e consolidação da pesquisa de satisfação de usuários, para fins de alcance de resultados paradigmáticos na gestão da operação.

Essas percepções foram confirmadas nos discursos dos entrevistados, pois repetitivamente eles se valeram de seleções lexicais como "adaptação"; "avaliação"; "benchmarking"; "desburocratização"; "eficácia"; "excelência"; e "gestão da qualidade".

A análise dos dados apontou que ainda há muitos pontos para serem aprimorados e desafios a serem enfrentados com o modelo em fase de consolidação e institucionalização. Os servidores entenderam a proposta do Gespública e concordam com a necessidade de melhorias; todavia, percebem que há limitações operacionais para sua implementação, nomeadamente por conta da orientação da instituição e sua complexa e burocrática cultura organizacional (Schein, 1985). De fato, no caso da Fiocruz, por conta de sua estrutura e processos rígidos (primeiro nível de análise da cultura organizacional), a implantação do Gespública deparou-se com resistência e barreiras, objeto de discussão do próximo bloco (4.2).

Ainda dentro dessa categoria, foram identificados três aspectos relevantes: (i) excelência dirigida ao cidadão, com direcionamento de suas ações para atendimento às expectativas da sociedade, que é o receptor dos serviços públicos de forma regular e contínua; (ii) apren- 
dizado organizacional, com a busca de novos conhecimentos por meio da percepção, reflexão, avaliação e compartilhamento das informações; e (iii) visão de futuro, visando um estado desejado e antecipando a organização às necessidades e demandas da sociedade.

No primeiro aspecto, foi diagnosticado o incentivo ao comprometimento de todos com a cultura da excelência na Fiocruz, originalmente marcado pelas boas práticas de gestão que evoluem na Instituição, e reforçado pela adesão formal da instituição aos critérios de excelência da gestão pública desde 2003, com aderência aos princípios do Programa de Qualidade na Gestão Pública.

No que se refere ao aprendizado organizacional, percebemos que a ênfase dada ao modelo de governança democrática participativa é o principal método de desenvolvimento do aprendizado organizacional na Fiocruz, que utiliza práticas de gestão promotoras do intercâmbio e da aprendizagem por meio das suas Câmaras Técnicas e Fóruns Temáticos, bem como com a realização de congressos, seminários, oficinas, grupos de estudo, sessões científicas e participação em redes nacionais e internacionais no campo das suas diversas ações, incluindo a área de gestão. Em relação à cultura da excelência, profissionais da Fiocruz foram qualificados no campo da gestão da qualidade e no Modelo de Excelência da Gestão Pública, assim como para realização de avaliação da gestão e de disseminação dos valores da organização, com a participação de cerca de 400 profissionais por ano.

Já no que tange à visão de futuro, a Fiocruz redefiniu os seus objetivos e metas, e propõe que em 2022 seja uma instituição pública e estratégica de saúde, reconhecida pela sociedade brasileira e de outros países por sua capacidade de colocar a ciência, a tecnologia, a inovação, a educação e a produção tecnológica de serviços e insumos estratégicos para a promoção da saúde da população, redução das desigualdades e iniquidades sociais, a consolidação e o fortalecimento do SUS e a elaboração e o aperfeiçoamento de políticas públicas de saúde.

Os gestores entrevistados acreditam que o Programa já cumpre alguns de seus objetivos, tendo em vista duas avaliações já realizadas, em dois ciclos, com levantamento de oportunidades/melhorias e elaboração de plano de ação, o que foi desvelado no fragmento de discurso do entrevistado 7, nomeadamente pela seleção lexical "ficamos com 419 pontos em um instrumento de 500 pontos":

Os trabalhadores e os gestores da Fiocruz fecharam todo o ciclo de avaliação. Na época, na avaliação em 2007, ficamos com 419 pontos em um instrumento de 500 pontos, o que era uma pontuação boa, excelente, pra gente começas e depois passar para instrumentos de 1.000 pontos. (...) Depois a Fiocruz elaborou o plano de melhoria e teve o desafio de fazer acontecer na primeira gestão. (Entrevistado 7)

Em geral, há satisfação com o resultado do programa, cujas metas foram consideradas difíceis, porém foram alcançadas; o que se constata nas seleções lexicais "elaborou o plano de melhoria e teve o desafio de fazer acontecer na primeira gestão" e "o que era uma pontuação boa, excelente", respectivamente. 
Na visão dos entrevistados, esse resultado positivo foi possível, pois o Gespública promoveu a eficiência e eficácia por meio do melhor aproveitamento de recursos na organização, com o aprimoramento de algumas práticas, conforme se apreende do seguinte fragmento de discurso: "A Gespública trouxe essa clareza pra gente. Hoje eu consigo produzir indicadores que de eficiência e eficácia, mas a gente produz indicadores de produtividade. Então, todo ano as áreas têm que ter essa consciência (Entrevistado 1)."

Nessa fala, as seleções lexicais "A Gespública trouxe essa clareza pra gente" e "hoje eu consigo produzir indicadores" reforçam a ideia de que a avaliação da administração pública brasileira se encontra institucionalizada basicamente na função do controle, principalmente, os ligados aos recursos financeiros, que é limitado, já que transita no curto caminho entre o previsto e o realizado (Camilo, 2003).

Ao longo da nossa vivência na Fiocruz e por meio de conversas informais, apreendemos que a gestão da qualidade é identificada nos dados, com amplitude de percepções, o que ficou patente no seguinte fragmento de discurso:

E o campo da qualidade, se a gente pudesse defini-lo, envolve obviamente tudo aquilo que a gente faz na nossa organização. Ela não deixa de ser um processo enriquecedor de todas as nossas atividades, qual seja como fazer mais e melhor aquilo que estamos designados para fazer melhor no sentido da busca eficiência, da busca da qualidade, do que a gente pode sintetizar, como entregar mais valor, mais qualidade à sociedade, seja ela representada por um indivíduo cidadão à porta de nossos serviços de saúde, seja a instituição Ministério da Saúde. (Entrevistado 2)

Neste fragmento de discurso, a utilização das seleções lexicais "qualidade" e "entrega de valor" revela a aquiescência de que existem múltiplas percepções, desejos e necessidades por parte dos destinatários (Velasques, 2006). Ficou patente que, para os membros do Comitê, os clientes não são somente os cidadãos que precisam dos seus serviços, mas também o Ministério da Saúde, conforme explicitado no fragmento lexical "como entregar mais valor, mais qualidade à sociedade, seja ela representada por um indivíduo cidadão à porta de nossos serviços de saúde, seja a instituição Ministério da Saúde". Assim, mais do que uma reflexão sobre a necessidade de melhoria da qualidade dos serviços oferecidos à população, para os servidores da Fiocruz, as políticas e práticas determinadas pelo Gespública foram percebidas como uma pressão institucional, burocrática e política, pois os resultados seriam avaliados não por uma "pesquisa de satisfação dos clientes", mas pelos superiores em Brasília.

A entrega desses valores preconizados pelo Gespública foi determinada pela adequabilidade ao programa das características institucionais da Fiocruz: sua missão, visão, valores, estruturas e processos.

O Gespública se adequou em bastante coisas [sic]. Me serviu pra conversar sobre resultados com o meu pessoal. E não é só conversar. Você mostra um referencial comparativo. Ele me serviu para indicar benchmarking. (Entrevistado 1) 
A maioria das unidades aqui não tem nada. Então, na realidade, não tem muito que adequar, é implantar mesmo. Eu acho que se adapta bem. (Entrevistado 6)

O que nós procuramos fazer foi integrar e adequar a lógica da divisão do projeto Gespública em áreas de conhecimento no campo da informação e organização. (Entrevistado 10)

Esses fragmentos de discursos desvelaram diferentes percepções sobre o processo de implantação do Gespública na Fiocruz; se, por um lado, inicialmente, a organização fora descrita como uma entidade de cultura e processos rígidos; por outro, estes interlocutores, por sua vez, percebem-na como pouco estruturada ("a maioria das unidades aqui não tem nada"). Portanto, entendemos que esses servidores não possuem referências suficientes para avaliar as implicações de um programa como o Gespública. Todavia, ao longo desta pesquisa, foi possível apreender as resistências, barreiras e dificuldades na implantação do programa, os quais são objeto do bloco que se segue.

\subsection{Resistências, barreiras e dificuldades na implantação do programa}

Nessa categoria, foram encontradas resistências na implantação do Programa, visto que há uma diferença latente entre os aspectos da burocracia e a aplicação do gerencialismo, conforme já apontado anteriormente (Paula, 2005).

No limite, as resistências, barreiras e dificuldades na implantação do programa apontadas pelos servidores foram causadas pela padronização de procedimentos, a descontinuidade política, a burocracia e a cultura da Fiocruz.

Conforme sugerido por Mechanic (1962), os servidores justificaram sua resistência de alinhamento aos processos preconizados no Gespública, valendo-se da complexidade dos mesmos. Por exemplo, um dos entrevistados asseverou que: “(...) a gente avançou, mas ainda não desenvolvemos os procedimentos para as iniciativas uniformizadas e disseminadas, o que dificulta a implementação do programa" (Entrevistado 1).

Nesse fragmento de discurso, fica patente a justificativa que os procedimentos demandados pelo Gespública são, por si só, uma barreira em sua implementação. De fato, por mais que a base da pirâmide empresarial entenda o que a alta administração e gerência demandam, ela não executa sine ira et studio as ordens emanadas de cima (Grin, 2014).

A criação de múltiplos processos, muitos deles redundantes, resulta em práticas de burocracias do nível da rua (Lipsky, 1980), uma vez que esses servidores desfrutam de ampla autonomia na decisão sobre as práticas e operações propriamente ditas. De fato, como já observado por Downs (1967), esses servidores não necessitaram violar as regras para não cumprir totalmente as ordens oriundas de cima.

Foi possível verificar que, ao longo desse processo, por conta de uma característica da Fiocruz, a rotatividade dos cargos de chefia, houve descontinuidade política, a qual acarretou outras dificuldades, conforme explicitado no fragmento de discurso seguinte: "Coloco tam- 
bém a descontinuidade política e o processo democrático aí quando mudam os gestores. Eles não foram treinados, então você tem uma parada aí, até eles entrarem na cultura" (Entrevistado 9).

O fragmento lexical "então você tem uma parada" indica que, sempre que ocorre uma mudança gerencial, há uma ruptura no fluxo de processos, até que o nosso gestor absorva a cultura organizacional. No caso do Gespública, as mudanças que ocorreram ao longo da implantação do programa resultaram no atraso do cronograma e, não raramente, no retrabalho e repensar de processos, que já haviam sido definidos.

Também pudemos identificar que a burocracia (Lipsky, 1980) revelou-se, pois, conforme afirmou o entrevistado 1, apesar de a Fiocruz ter uma estrutura organizacional híbrida e um modelo de grande autonomia entre as unidades, principalmente a de Produção, a burocracia ainda persiste: “(...) na área de gestão de processos de apoio continuam talvez com os mesmos processos de apoio de décadas atrás, totalmente burocratizados" (Entrevistado 1).

Esse fragmento de discurso reforça a existência de resistência dos servidores, reificada nas burocracias do nível da rua (Lipsky, 1980), as quais estão arraigadas na cultura organizacional. Nesse sentido, a Gespública, como exemplo da Nova Gestão Pública (NGP), não cumpriu totalmente a promessa de erradicar o excesso de procedimentos (Sano e Abrúcio, 2008), pois focou exclusivamente no redesenho dos processos organizacionais, negligenciando a cultura organizacional da Fiocruz, a qual ainda se alicerça em traços, descritos por Pires e Macedo (2006:83), como a "luta de forças [que] se manifesta entre o novo e o velho, ante uma dinâmica e uma burocracia arraigada", ou seja, a existência de uma cultura excessivamente burocrática nas organizações públicas, fato que naturalmente gera a resistência. Essa percepção foi explicitada no seguinte fragmento de discurso:

"Velhas práticas, velhos poderes, novas práticas, nem sempre novos poderes." (...) revela um pouco o que eu quero dizer falando diretamente sobre cultura organizacional. Mas as pessoas sempre têm uma forma de fazer as coisas. Quando você pretende mudar, mudar de forma coletiva como o Gespública está propondo, vem a resistência. (Entrevistado 2)

As seleções lexicais "as pessoas sempre têm uma forma de fazer as coisas" e "mudar de forma coletiva" são as que os programas que visam à modificação do gerenciamento da qualidade devem focar na mudança da cultura organizacional, de tal forma que as relações institucionais sejam modificadas, e os chefes e subordinados se transformem em parceiros que busquem atingir as metas da organização (Gomes, 1997).

\subsection{Influência das diretrizes do Gespública}

A influência das diretrizes do Gespública relaciona-se às ações diretas realizadas para a busca da excelência, de acordo com os valores institucionais da organização, buscando a qua- 
lidade e melhoria dos seus processos, cumprimento de prazos e melhorias na organização em termos de gestão e infraestrutura. As principais influências citadas pelos entrevistados foram: a metodologia do programa em si, aprendizado, avaliação, os indicadores de resultados e a carta de serviços.

O primeiro aspecto citado ressalta a importância da metodologia do programa, já que ele agrega valor e faz com que o programa aconteça na prática, o que foi evidenciado nos seguintes fragmentos de discursos:

A própria metodologia do Gespública já gerava um impacto de maior integração, discussão, foco em plano de melhorias, discussão de nós críticos, integração da área técnico-administrativo com a técnico-científica e reconhecimento institucional. (Entrevistado 2)

Hoje eu acho que nós estamos com maior maturidade na Fiocruz de entender que o mapeamento de processo é uma camada basal, estruturante, para melhoria da gestão. (...) E eu acho que é isso que a Gespública traz. (Entrevistado 10)

De fato, apesar das barreiras e resistências, no final, o Gespública levou ao repensar das práticas organizacionais na Fiocruz, e seus servidores reconheceram um ganho de eficiência e eficácia, conforme desvelado nas seleções lexicais "maior integração da área técnico-administrativa com a técnico-científica" e "maior maturidade na Fiocruz de entender que o mapeamento de processo é uma camada basal, estruturante, para melhoria da gestão".

O Gespública também impactou o aprendizado organizacional dentro da Fiocruz, já que foi necessária a realização de um esforço no investimento e na capacitação de seus servidores e empregados celetistas, como explicitado no Relatório de Autoavaliação Fiocruz ciclo 2010/2011. Nesse documento, a organização reconhece, como o principal método de desenvolvimento e aprendizagem organizacional da organização, o modelo de governança democrática participativa, o qual recorre a práticas prescritas pelo Gespública, por meio das Câmaras Técnicas e Fóruns Temáticos, bem como a realização de congressos, seminários, oficinas, grupos de estudo e sessões científicas.

Esta nova transparência nos processos se fez presente nas falas dos entrevistados, como nesse fragmento de discurso: "Eu tento fazer, deixando escrito com as pessoas o aprendizado, porque não adianta também só credenciar, pois, se ficar aquele clubinho, volta tudo o que era antes. Então continua [o aprendizado], porque o credenciamento passa por isso" (Entrevistado 1).

As seleções lexicais "eu tento fazer, deixando escrito" e "volta tudo o que era antes" permitem-nos inferir que as mudanças, promovidas pelo Gespública, foram percebidas e valorizadas pelos servidores, principalmente pela percepção de que agora o aprendizado passa a ser continuado e disseminado.

A rigor, os servidores entendem que a busca por um sistema integrado de aprendizagem deve ser constante, com o objetivo de incentivar a inovação para área de gestão, como 
desvelado no seguinte fragmento de discurso, nomeadamente pela seleção lexical "é o que a gente busca para uma inovação gerencial": "Instituir um aprendizado onde as decisões da organização sejam baseadas em evidências, onde a gente tenha o nosso modelo de governança institucional realmente embasado em gestão e conhecimento, que é o que gente busca para uma inovação gerencial" (Entrevistado 7).

Outra influência das diretrizes do Gespública que se fez presente foi a aplicação de métricas e índices de resultados para se avaliar a qualidade do trabalho do servidor, conforme atestado no seguinte fragmento de discurso:

Tenho minha estimativa para o final do ano. E sei que no final do ano eu quero entregar um bom resultado de produção: quantos por cento eu abri; quantos empenhos eu emiti. Mas a gente também agora, já faz um tempinho, já vem pensando nos indicadores de resultados..., qual o impacto do meu trabalho nas outras áreas. (Entrevistado 1)

A seleção lexical "pensando nos indicadores de resultados, qual o impacto do meu trabalho nas outras áreas", mesmo que refraseada, foi comum em muitas falas de servidores e celetistas, que reconhecem no estabelecimento de parâmetros de eficiência e eficácia a fonte de satisfação com o seu trabalho.

No limite, a adoção dessas métricas de aferição de resultados resultou no aprimoramento dos processos, fator fundamental na identificação de oportunidades de melhorias.

\subsection{Comprometimento com a gestão pública por resultados}

A alta direção da organização participa efetivamente e respalda a implementação do programa de gestão, conforme atestado no documento de referência do VI Congresso interno:

Assume-se por princípio que a necessidade de aprimoramento do modelo de gestão deve ser permanente, sendo inclusive objetivo da própria gestão, independentemente do modelo jurídico que venha a ser proposto e alcançado, considerando-se as diversas áreas de trabalho institucional, sejam de caráter administrativo geral ou técnico específicos e finalísticos.

Esse compromisso da alta administração jaz na crença de que enriquecer a cadeia de valor da Fiocruz é o melhor caminho para se dar respostas mais eficientes e eficazes à sociedade.

De fato, ao longo das entrevistas, ficou evidente que os servidores e celetistas percebem a existência desse comprometimento, nomeadamente, quando se refere a inovação da gestão, integração das áreas e processos, valorização e capacitação do pessoal.

A rigor, todos os aspectos citados vão ao encontro dos valores institucionais da organização, levando-se em consideração a disseminação da cultura de excelência como valor cultural intrínseco da organização, ou seja, esses valores são internalizados e ressaltados 
pelos entrevistados, como o comprometimento da alta direção para o desenvolvimento de atividades conforme explicitado no seguinte fragmento de discurso: "O programa ganha um fortalecimento muito grande da alta direção e ganha também apoio financeiro com um projeto específico de gestão, que permite que a gente possa fazer esse trabalho aqui" (Entrevistado 7).

A integração, a partir da participação de pessoas nos fóruns de discussão, torna as decisões mais institucionalizadas com o objetivo de minar as resistências. Um exemplo disso é a aproximação entre áreas técnicas e de gestão:

Certamente há essa divisão técnico-administrativa, técnico-científica, mas a gente procura cada vez mais diminuir a distância entre elas, mas ainda existe muita coisa pra ser feita. Mas hoje quando você coloca dentro de uma sala, nas oficinas da Gespública, unidades técnico-científicas e de várias áreas pra discutir modelos, formas de gestão, aprimoramento etc., você está gerando o impacto já direto da integração que o Gespública pode e vem promovendo na discussão sobre as práticas de gestão da organização. (Entrevistado 2)

Outro destaque diz respeito à valorização de pessoas e ao mapeamento de suas competências, resultado do Plano de Melhorias que foi implantado ao longo do processo:

Mas então você tem essas pessoas, a partir de um banco de talentos, digamos assim, sendo alocadas de forma mais direcionada, para prestar melhores serviços, poder ter a apropriação de suas competências de forma mais adequada. Isso está relacionado com excelência, está relacionado com melhoria dos processos, isso não era feito antes. (Entrevistado 2)

A capacitação é outro fator determinante para a qualidade e sucesso do programa e para a organização como um todo, em que se percebeu uma maior valorização de treinamento e qualificação: “(...) um programa mais efetivo de capacitação, para as próprias pessoas entenderem a qualidade no seu trabalho" (Entrevistado 1); “(...) que permite que a gente possa estar fazendo esse trabalho aqui, de capacitação, 400/ano na gestão da qualidade" (Entrevistado 7).

Durante a análise dos dados, foi possível perceber a repetição de palavras-chave em diferentes categorias por diferentes entrevistados, e trianguladas com os documentos encontrados, o que demonstra a integração sobre os temas. Algumas repetições referem-se a aspectos identificados como necessários e pouco desenvolvidos, como a formalização de processos, de planos, controles e avaliações de resultados. Os aspectos mais desenvolvidos são o papel da alta administração no que diz respeito ao comprometimento e responsabilidades acerca de suas demandas institucionais, na qualificação de pessoas, ao atendimento de seus compromissos legais e de integração.

Constata-se também que Integração, Inovação, Gestão Baseada em Processos, Controle Social e Gestão Participativa foram aspectos citados pela maioria dos entrevistados nas dife- 
rentes questões, o que demonstra a percepção dos entrevistados acerca dos fundamentos da excelência em gestão pública.

\section{Conclusões}

A principal contribuição deste artigo reside em ampliar o conhecimento sobre a influência do Gespública no serviço público, particularmente, em uma organização complexa e burocrática como a Fiocruz, reconhecida pela sua excelência em prestação de serviços. O objetivo da pesquisa foi identificar e analisar, na percepção dos respondentes, triangulados com os documentos fornecidos e nossas observações, os resultados da aplicação do Modelo de Excelência na gestão Pública (MEGP) na Fundação Oswaldo Cruz (Fiocruz) buscando avaliar os principais obstáculos culturais, burocráticos e políticos, conforme o Programa Nacional de Gestão Pública (Gespública) do MPOG, vis-à-vis as diretrizes organizacionais. Para atingir esse objetivo, foram estruturadas as seguintes categorias de análise: (i) implantação e adequação ao Gespública; (ii) resistências, barreiras e dificuldades na implantação do programa; (iii) impactos; e (iv) comprometimento com a gestão pública por resultados.

Com relação à implantação e adequação ao Gespública foi possível verificar que, de forma geral, os resultados da implantação na Fiocruz podem ser assim sintetizados: (i) o programa já cumpre parcialmente seus objetivos, pois verificam-se melhorias decorrentes de sua implantação; (ii) comprovou-se que os entrevistados têm suas percepções sobre qualidade, buscam resultados e desenvolvem atividades no sentido de aprimorar suas práticas; (iii) verificou-se também a importância das pessoas enquanto participantes do processo e de aspectos como comprometimento e engajamento, quebrando as resistências; (iv) o processo de autoavaliação destaca as melhores práticas e as oportunidades de melhoria e faz com que a organização, a cada ciclo, se desafie para que seus resultados alcancem um nível de gestão cada vez mais alto; (v) o compromisso da alta direção explicita-se em investimentos voltados para a cultura da excelência com suas estratégias e planos formulados a partir de um processo de avaliação construído de forma participativa.

No entanto, constata-se que há ainda aspectos a serem aprimorados e desafios a serem enfrentados para a consolidação e institucionalização do programa. Os achados da pesquisa apontam para a necessidade de melhorias; todavia, apontam também a existência de limitações operacionais para sua plena implementação, nomeadamente por conta da orientação da instituição e sua burocrática e complexa cultura organizacional.

No tocante às resistências, barreiras e dificuldades na implantação do programa, percebese que as mesmas foram causadas principalmente pela padronização de procedimentos, descontinuidade política, burocracia e a cultura da Fiocruz. Em contrapartida, foi possível identificar os aspectos pouco desenvolvidos que configuram-se como oportunidades de melhoria como: (i) a necessidade de fortalecer a formulação de processos, de planos, de controle e avaliações de resultados e consequente padronização; (ii) a pactuação de metas para a sensibilização do corpo 
de servidores e colaboradores; (iii) a cultura burocrática como uma barreira na adesão ao programa corporativamente, pois a instituição possui unidades autônomas com desenvolvimento maior ou menor em detrimento da outra, dificultando a integração dos processos de gestão; e (iv) o feedback em relação ao Plano de Melhoria com o objetivo de se terem iniciativas uniformizadas para se mapearem os processos e criar oportunidades de melhoria.

Com referência à influência das diretrizes do Gespública foi possível comprovar que as ações diretas realizadas para a busca da excelência alcançaram boa aderência aos valores institucionais da organização, buscando a qualidade e a melhoria dos seus processos, o cumprimento de prazos e o avanço da organização em termos de infraestrutura e de gestão. As principais influências citadas foram: a metodologia do programa, os indicadores de resultados, o aprendizado, a avaliação e a carta de serviços, impactando positivamente o aprendizado organizacional.

No que diz respeito ao comprometimento com a gestão pública por resultados, ficou claro que a alta direção da Fiocruz participa efetivamente e respalda a implementação do programa de gestão, o que facilitou de maneira decisiva sua implantação. Constata-se que integração, inovação, gestão baseada em processos, controle social e gestão participativa foram aspectos onde houve maior esforço da alta administração visando alcançar a melhoria dos fundamentos da excelência em gestão pública.

Por fim, observa-se que o modelo de excelência estudado se torna um importante instrumento para as organizações públicas que desejem qualificar seus serviços, não sendo um pré-requisito o alinhamento total com o modelo, como se verificou neste estudo, pois as organizações podem se adaptar de acordo com seu escopo e especificidades, tendo, no entanto, como principal desafio a adequação das métricas do Gespública à cultura organizacional.

Como agenda para futuras pesquisas, sugere-se a ampliação desta análise confrontando instituições que receberam premiações do MPOG, para estabelecer uma relação entre a adoção desse programa e o aumento da eficiência das organizações da administração pública.

\section{Referências}

ABRÚCIO, Fernando L. O impacto do modelo gerencial na administração pública: um breve estudo sobre a experiência internacional recente. Cadernos Enap, n. 10, 1997.

AKIM, Érica K.; MERGULHÃO, Ricardo C. Panorama da produção intelectual sobre a medição de desempenho na gestão pública. Rev. Adm. Pública, v. 49, n. 2, p. 337-366, mar./abr. 2015.

BALDRIGE [online]. The Foundation for the Malcolm Baldrige National Quality Award. Disponível em: <www.baldrigepe.org/>. Acesso em: 20 maio 2014.

BARDIN, Laurence. Análise de conteúdo. Lisboa: Edições 70, 1977.

BARZELAY, Michael. Breaking through bureaucracy. Berkeley: University California Press, 1994. 
BECHTEL, William. Taking the naturalistic turn, or, how real philosophy of science is done. Chicago: University of Chicago Press, 1993.

BRASIL. Ministério da Administração Federal e Reforma do Estado. Programa da qualidade e participação na administração pública. Brasília: Mare, 1997.

BRELAZ, Gabriela de; ALVES, Mário Aquino. O processo de institucionalização da participação na Câmara Municipal de São Paulo: uma análise das audiências públicas do orçamento (1990-2010). Rev. Adm. Pública, v. 47, n. 4, p. 803-826, jul./ago. 2013.

BRESSER-PEREIRA, Luiz Carlos. Construindo o Estado republicano: democracia e reforma da gestão pública. Rio de Janeiro: Editora FGV, 2009.

BRESSER-PEREIRA, Luiz Carlos. O modelo estrutural de gerência pública. Rev. Adm. Pública, Rio de Janeiro, v. 42, n. 2, p. 391-410, mar./abr. 2008.

BRESSER-PEREIRA, Luiz Carlos; SPINK, Peter K. Reforma do Estado e administração pública gerencial. 4. ed. Rio de Janeiro: Editora FGV, 2001.

BRESSER-PEREIRA, Luiz Carlos; SPINK, Peter K. Reforma do Estado e administração pública gerencial. 7. ed. Rio de Janeiro: Editora FGV, 2006.

BRESSER-PEREIRA, Luiz Carlos; SPINK, Peter K. (Org.). Reforma do Estado e administração pública gerencial. Revista do Serviço Público, ano 47, v. 120, n. 1, p. 7-29, jan./abr. 1996.

CAMILO, Ronald D. Modelagem dinâmica da gestão: passos para a excelência e resultados superiores. Belo Horizonte: Instituto Qualidade Minas, 2003.

CARR, David; LITTMAN, Ian D. Excelência nos serviços públicos: gestão da qualidade total na década de 90. Rio de Janeiro: Qualitymark, 1992.

CROSBY, Philip. Quality is free. Nova York: McGraw-Hill, 1979.

DEMING, Edward. Qualidade: a revolução na administração. Rio de Janeiro: Marques Saraiva, 1990.

DOWBOR, Landislau. A reprodução social. Petrópolis: Vozes, 1998.

DOWNS, Anthony. Inside bureaucracy. Illinois: Waveland Press, 1967.

EVANS, James R.; LINDSAY, William M. "5: Total quality management", the management and control of quality. 4. ed. Minneapolis, Minnesota: West Publishing, 1993.

FARMER, David J. Schopenhauer's porcupines: hegemonic change in context. Adm. Theory \& Praxis, v. 20, n. 4, p. 422-433, 1998.

FAVERO, Claudio G. Avaliação de programas públicos. Sistema de Avaliação do Programa Nacional de Gestão Pública e Desburocratização Aplicada à Marinha do Brasil — o caso do Programa Netuno. Dissertação (mestrado em administração pública) — Fundação Getulio Vargas, Rio de Janeiro, 2010.

FERREIRA, André R. Análise comparativa do prêmio qualidade do governo federal com outros prêmios nacionais e internacionais de qualidade. Dissertação (mestrado em administração pública). — Fundação Getulio Vargas, Rio de Janeiro, 2003. 
FERREIRA, André R. Modelo de excelência em gestão pública. Revista Eixo, v. 1, n. 1, p. 31-43, 2012. FIOCRUZ, Relatório de atividades. 2005-2008. 2009.

FISCHER, Tânia. Administração pública como área de conhecimento e ensino: a trajetória brasileira. Revista de Administração de Empresas, v. 24, n. 4, p. 278-88, 1984.

FISCHER, Tânia. A formação do administrador brasileiro na década de 90: crise, oportunidade e inovações nas propostas de ensino. Rev. Adm. Pública, v. 27, n. 4, p. 11-20, 1993.

FLEURY, Sonia et al. Análise do perfil dos artigos publicados na Revista de Administração Pública RAP — no período 1992-2002. Rio de Janeiro: Ed. EAESP/FGV, 2003.

FOWLER, Eliane D.; MELLO, Carlos H. P.; COSTA NETO, Pedro L. O. Análise exploratória da utilização do programa de qualidade Gespública nas instituições federais de ensino superior. Gestão \& Produção, v. 18, n. 4, p. 837-852, 2011.

GOLDFINCH, Shaun; WALLIS, Joe. Two myths of convergence in public management reform, Public Administration, v. 88, n. 4, p. 1099-1115, 2010.

GOMES, Ricardo C. Análise exploratória da perspectiva de implantação da filosofia da qualidade na administração pública. Rev. Adm. Pública, v. 31, n. 3, p. 48-58, 1997.

GOTTSCHALK, Louis. Content analysis of verbal behavior: new findings and clinical applications. Hillside, NJ: Lawrence Erlbaum Associates, 1995.

GRIN, Eduardo José. O Programa Nacional de Gestão Pública e Desburocratização (Gespública): os nexos com a trajetória de políticas prévias e com a administração pública gerencial. In ENANPAD, XXXVII, 2013, Rio de Janeiro Anais... Rio de Janeiro: Anpad, 2013.

GRIN, Eduardo José. Trajetória e avaliação dos programas federais brasileiros voltados a promover a eficiência administrativa e fiscal dos municípios. Rev. Adm. Pública, v. 48, n. 2, p. 459-480, mar./ abr. 2014.

HAQUE, Shamsul. Impacts of globalization on the role of the State and bureaucracy in Asia. Adm. Theory \& Praxis, v. 20, n. 4, p. 439-451, 1998.

JURAN, Joseph M. Architect of quality: the autobiography of dr. Joseph M. Juran. Nova York City: McGraw-Hill, 2004.

KARYOTAKIS, Konstantinos M.; MOUSTAKIS, Vassilis. Reinvention of the public sector: total quality management and change management. Singidunum Journal Of Applied Sciences, v. 11, n. 2, p. 30-44, 2014.

KEINERT, Tania M. M. Administração pública no Brasil: crises e mudanças de paradigmas. São Paulo: Annablume; Fapesp, 2000.

KOUZMIN, Alexander. Symposium: globalization and public administration — enhancing dismantling or protecting distinctive administrative capacity? Adm. Theory \& Praxis, v. 20, n. 4, p. 434-438, 1998.

LIMA, Paulo D. B. Excelência em gestão pública: a trajetória e a estratégia do Gespública. Rio de Janeiro: Qualitymark, 2007. 
LIPSKY, Michael. Street-level bureaucracy: dilemmas of the individual in public services. Nova York: Russel Sage Foundation, 1980.

LUEDY, Almerinda; MENDES, Vera L. P. S.; RIBEIRO-JÚNIOR, Hugo. Gestão pública por resultados: contrato de gestão como indutor de melhorias em um hospital universitário. Revista Organizações \& Sociedade, v. 19, n. 63, p. 641-659, 2012.

MALIK, Ana; SCHIESARI, Laura. Qualidade na gestão local de serviços e ações de saúde. São Paulo: FSP, 2002.

MACHADO-DA-SILVA, Clóvis; AMBONI, Nério; CUNHA, Vera C. Produção acadêmica em administração pública: período 1983-88. In: ENANPAD, XVIII, 1989, Belo Horizonte. Anais... Belo Horizonte: Anpad, 1989.

MECHANIC, David. Sources power of lower participants in complex organizations. Administrative Science Quarterly, v. 7, n. 3, p. 349-364, 1962.

MELLO, Márcio L. B. C.; AMANCIO FILHO, Antenor. A gestão de recursos humanos em uma instituição pública brasileira de ciência e tecnologia em saúde: o caso Fiocruz. Rev. Adm. Pública, v. 44, n. 3 p. 613-36, 2010.

MELLO, Marcus A. Reformas constitucionais no Brasil: instituições políticas e processo decisório. Brasília, DF: Revan, 2002.

MERRIAN, Sharan B. Qualitative research and case study applications in education. San Francisco: Jossey-Bass Publisher, 1998.

MPOG. Ministério do Planejamento e Gestão. 2010. Disponível em: <www.gespublica.gov.br/ biblioteca/pasta.2010-12-08.2954571235/o_programa_gespublica_e_um_modelo_de_gestao_para_o_brasil.....pdf >. Acesso em: 13 set. 2014.

MPOG. Secretaria de Gestão. Balanço das principais ações realizadas de janeiro de 2008 a julho de 2009. 2009a.

MPOG. Secretaria de Gestão. Melhoria da gestão pública brasileira por meio da definição de um guia referencial para medição de desempenho da gestão, e controle para o gerenciamento dos indicadores de eficiência, eficácia e de resultados do Programa Nacional de Gestão Pública e Desburocratização. Brasília: MP; SEGES, 2009b.

MPOG. Secretaria de Gestão. Programa Nacional de Gestão Pública e Desburocratização — GesPública; Prêmio Nacional da Gestão Pública - PQGF. Carta de serviços ao cidadão. Brasília: MPOG; Seges, 2009c. Versão 1/2009.

MPOG. Secretaria de Gestão. Programa Nacional de Gestão Pública e Desburocratização — GesPública; Prêmio Nacional da Gestão Pública — PQGF. Documento de referência: Fórum Nacional 2008/2009. Brasília: Ministério do Planejamento, Orçamento e Gestão, Subsecretaria de Planejamento, Orçamento e Gestão; MP; SEGES, 2009d.

MPOG; MF; SERPRO. Programa Nacional de Gestão Pública e Desburocratização — GesPública. Guia de gestão de processos do governo. Brasília: maio 2011. MPOG: Serpro. Disponível em: <www. 
serpro.gov.br/noticias/guia-de-gestao-de-processos-de-governo-e-lancado-em-maio > . Acesso em: 13 set. 2014.

NEUENDORF, Kimberley. The content analysis guidebook. Thousand Oaks: Sage, 2012.

OLIVEIRA, Antonio. Burocratas da linha de frente: executores e fazedores das políticas públicas. Rev. Adm. Pública, v. 46, n. 6, p. 1551-1573, nov./dez. 2012.

PALADINI, Edson P. Gestão da qualidade: teoria e prática. 2. ed. São Paulo: Atlas, 2009.

PAULA, Ana P. P. Por uma nova gestão pública: limites e potencialidades da experiência contemporânea. Rio de janeiro: Editora FGV, 2005.

PIRES, José C. S.; MACEDO, Katia B. Cultura organizacional em organizações públicas no Brasil. Rev. Adm. Pública, v. 41, n. 1, p. 81-105, jan./fev. 2006.

POTTER, W. James; LEVINE-DONNERSTEIN, Deborah. Rethinking validity and reliability in content analysis. Journal of Applied Communication Research, v. 27, n. 3, p. 258-284, 1999.

PRESTES MOTTA, Fernando; CALDAS, Miguel. Cultura organizacional e cultura brasileira. São Paulo: Atlas, 1997.

REEVES, Carol A.; BEDNAR, David A. Defining quality: alternatives and implications. Academy of Management Review, v. 19, n. 3, p. 419-445, 1994.

RESENDE-JÚNIOR, Pedro C. Desempenho organizacional no setor público: análise do programa Gespública. In ENANPAD, XXXVII, 2013, Rio de Janeiro. Anais... Rio de Janeiro: Anpad, 2013.

ROSSI, Carlos A. V.; SLONGO, Luiz A. Pesquisa de satisfação de clientes: o estado-da-arte e proposição de um método brasileiro. Revista de Administração Contemporânea, v. 2, n. 1, p. 101-125, 1998.

SANO, Hironubu; ABRÚCIO, Fernando L. Promessas e resultados da nova gestão pública no Brasil: o caso das organizações sociais de saúde em São Paulo. Revista de Administração de Empresas, v. 48, n. 3, p. 64-80, 2008.

SCHEIN, Edgar H. Organizational culture and leadership: a dynamic view. San Francisco, CA: Jossey-Bass, 1985.

SELZNICK, Phillip. Foundations of the theory of organizations. American Sociological Review, v. 13, n. 1, p. 25-35, 1948.

SOUZA, Antonio R.; ARAÚJO, Vinicius C. O estado da reforma: balanço da literatura em gestão pública. Revista do Serviço Público, v. 54, n. 2, p. 61-98, 2003.

STILES, William B. Clasificación de actos ilocutivos intersubjetivos. Anuario de Psicología, v. 59, n. 4, p. 79-103, 1993.

TEIXEIRA, Hélio; SANTANA, Solange. Remodelando a gestão pública. São Paulo: Edgard Blücher, 1995.

VELASQUES, Angélica S. Avaliação dos critérios de excelência em organizações públicas e privadas. Dissertação (mestrado em administração pública). — Fundação Getulio Vargas, Rio de Janeiro, 2006. 
WEINBERG, Gerald M. Quality software management: volume 1. Systems thinking 1. Nova York: New York, 1991.

Fernando Filardi tem pós-doutorado em administração pela Universidade de São Paulo (FEA/USP) e é professor do Programa de Mestrado em Administração do Ibmec (RJ). E-mail: fernando.filardi@ibmecrj.br.

Angilberto Sabino de Freitas é doutor em administração pela Pontifícia Universidade Católica do Rio de Janeiro (PUC-RJ) e professor do Mestrado em Administração da Universidade do Grande Rio (UNIGRANRIO). E-mail: angilberto.freitas@gmail.com.

Helio Arthur Irigaray é doutor em administração pela Fundação Getulio Vargas (FGV/EAESP) e professor do Mestrado Executivo em Gestão Empresarial da Escola Brasileira de Administração Pública e de Empresas da Fundação Getulio Vargas (FGV/EBAPE). E-mail: helio.irigaray@fgv.br.

Ana Beatriz Ayres é mestre em administração pela Universidade do Grande Rio (UNIGRANRIO) e trabalha na Fundação Oswaldo Cruz (Fiocruz). E-mail: biaayres@fiocruz.br. 